\title{
Traditional Chinese herb, Astragalus: possible for treatment and prevention of COVID-19?
}

\author{
SIUKAN LAW ${ }^{1 *}$, CHUIMAN LO $^{1 \oplus}$, JIE HAN $^{1 \oplus}$, ALBERT WINGNANG LEUNG $^{2}$, CHUANSHAN XU $^{3 \odot}$
}

\author{
${ }^{1}$ Department of Science \\ School of Science and Technology \\ The Open University of Hong Kong \\ Ho Man Tin, Kowloon, Hong Kong \\ ${ }^{2}$ School of Graduate Studies \\ Lingnan University \\ Tuen Mun, Hong Kong \\ ${ }^{3}$ Key Laboratory of Molecular Target and Clinical Pharmacology \\ State Key Laboratory of Respiratory Diseases \\ School of Pharmaceutical Sciences \& Fifth Affiliated Hospital \\ Guangzhou Medical University \\ Guangzhou 511436, China
}

*Corresponding author: e-mail: siukanlaw@hotmail.com

\section{Summary}

Astragalus is a traditional herb which has been used in China for a long time. It regulates blood circulation (vital energy), invigorates body fluid circulation, protects the flow of blood to fight against the attack of pathogens, and strengthens "blood deficiencies" according to Bencao Congxin. Astragalus was approved by the Food and Drug Administration in 2009 as a dietary supplement for upper respiratory infections, allergic rhinitis (hay fever), asthma, chronic fatigue syndrome, and chronic kidney disease. Thirty journals published in the past ten years were reviewed by using library search engines such as SCI/SCIE, PubMed, and Scopus. In this mini-review, we focus on the anti-inflammatory of Astragalus features, discuss the background of Astragalus and its function in various diseases from water-extracted Astragalus membranaceus, Astragalus saponins, and Astragalus polysaccharides. Based on the traditional Chinese medicine theory, Astragalus is a potential candidate to treat and prevent COVID-19.

Key words: Astragalus, traditional Chinese herb, treatment, prevention, COVID-19

Słowa kluczowe: Astragalus, traganek, tradycyjna chińska roślina lecznicza, leczenie, zapobieganie, COVID-19 


\section{INTRODUCTION}

Severe acute respiratory syndrome caused by coronavirus 2 (SARS-CoV-2) was identified in December 2019 and named as coronavirus disease 2019 (COVID-19) by the World Health Organization (WHO). On the $11^{\text {th }}$ of March, a global pandemic has been announced [1]. The human-to-human transmission rate of COVID-19 by droplets or direct contact is extremely high [2]. There were more than 24,190,116 cases of infection up to the $27^{\text {th }}$ of August, 2020 [3]. Limited information concerning severe acute respiratory syndrome coronavirus 2 including its genomics, structural biology, virology, pathology, epidemiology, and the specific immune response, vaccine development becomes a huge challenge for scientists [4]. Thus, there is no vaccine for COVID-19 as of today [mid2020, Editorial note]. Traditional Chinese medicine is one of the possible ways that may replace vaccines. Many traditional Chinese herbal decoctions such as Qingfei paidu decoction and Gan cao gan jiang decoction, She gan ma huang decoction and Qingfei Touxie Fuzheng decoction are implied for the treatment of COVID-19 without side effects [5]. Recently, investigations on a single traditional Chinese herb, Astragalus (Huang Qi) for the treatment and prevention of COVID-19 got started (fig. 1). of flowering plants with over 1,750 species. Huang $Q i$ was classified as a high-class herb 2000 years ago based on the Shen Nong Ben Cao Jing. Huang is the "yellow" interior of the root and " $Q i$ " is the superior tonic roots termed as "leader" [6]. According to Bencao Congxin [7], Astragalus acts as traditional Chinese medicine regulating blood (vital energy), invigorating the body fluids, preparing the flow of blood to fight against the attack of external evils (pathogens), and strengthens body defences, which regulates the blood exhaustion and mainly uses to treat syndromes of various "blood deficiencies" in spleen, stomach, and lungs. It also has been promoted as a dietary supplement for upper respiratory infections, allergic rhinitis (hay fever), asthma, chronic fatigue syndrome, and chronic kidney disease that was approved by Food and Drug Administration in 2009 [8].

\section{Water extract of Astragalus membranaceus root}

The water extract of $A$. membranaceus root was found to have an antiviral activity for the treatment and prevention of common cold [9]. It enhanced the immune system and production of immunoglobulin to restore the loss of T-cells during viral upper respiratory infections [10]. There was

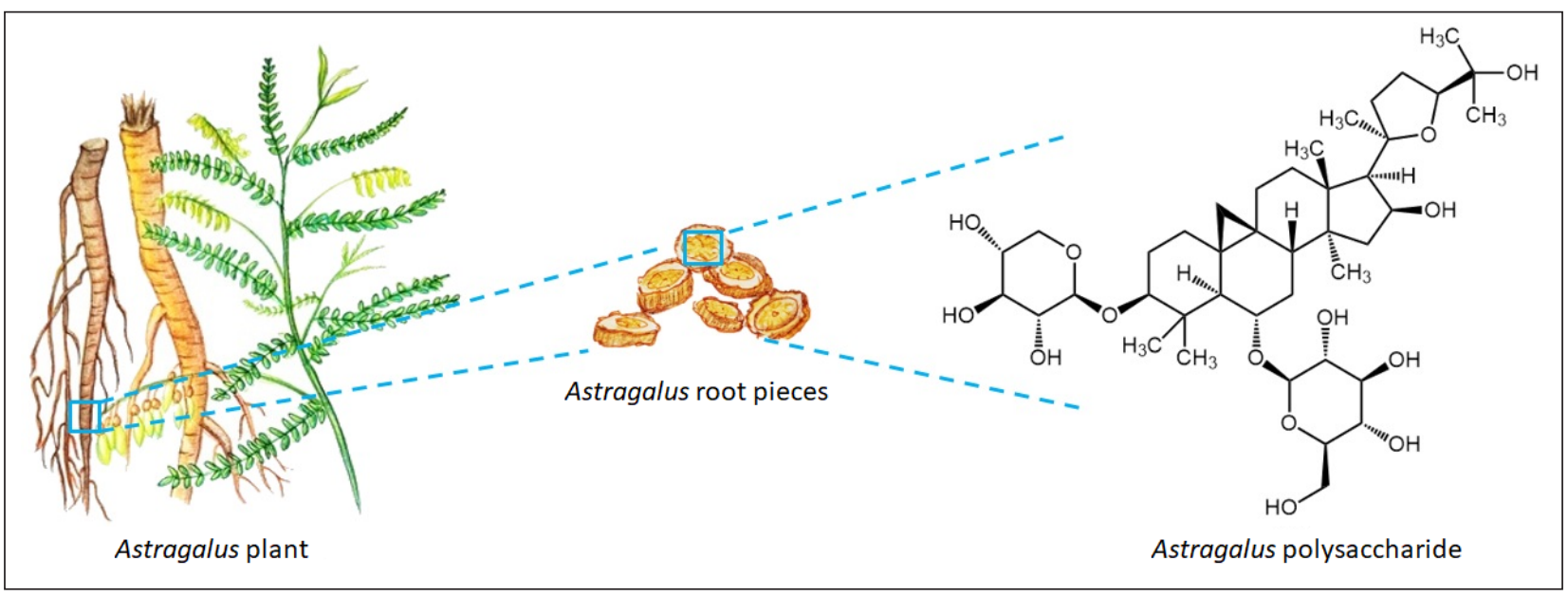

Figure 1.

Possible Astragalus form used for the treatment and prevention of COVID-19.

Design and diagram draw by Dr. Chuiman Lo.

\section{ASTRAGALUS (HUANG QI)}

Astragalus derived from the root of Leguminosae plant called Astragalus membranaceus (Fisch.) Bunge or Astragalus mongholicus (Bunge) P. K. Hsiao with Latin name Radix Astragali. These are the largest genera an effect on water extract of $A$. membranaceus root in TH cell subset function in children with recurrent tonsillitis. This had an important significance in the treatment of recurrent tonsillitis and improved TH1 cell subset function because the level of interferon-gamma (IFN-gamma) increased 
and decreased the level of interleukin-4 (IL-4) [11]. Moreover, the clinical trials had shown that A. membranaceus root could stimulate and rejuvenate depressed immune function. It significantly stimulated the number of white blood cells in healthy volunteers administered orally with $8 \mathrm{~g}$ of A. membranaceus root per day for 2 months. It also increased the IgM, IgE, and cAMP in the blood of healthy adults in 20 days [12]. In another clinical study, with the same dose and time of administration, the water extract of $A$. membranaceus root indicated an immune-supporting effect on the macrophage phase. It acted as a natural killer of inhibition of the activity in T-helper cell type 2 cytokines [13]. In most studies it was proven that Astragalus was an immune tonifying herb for lung, increasing the resistance against respiratory infections mediated by humoral and cell-immunity [14].

In 2011, Lin Y et al. showed that the extract of Astragalus root administered orally played an important role in preventing the recurrence of asthma in 90 children. It significantly increased the levels of peak expiratory flow rate (PEFR) and immunoreactive fibronectin-gamma (IFN-gamma) but decreased the level of interleukin-4 (IL-4) [15]. Late in 2013, Zou C et al. discovered that $2.25 \mathrm{~g}$ of $A s$ tragalus granules (equivalent to $15 \mathrm{~g}$ of crude $A s$ tragalus root) administered twice a day, at least for 3 to 6 months improved the immune function, enhanced the serum level of $\operatorname{IgG}$, and prevented the relapse of nephrotic syndrome by reducing the incidence of upper respiratory tract infection (URTI) in children [16]. After 2016, Su G et al. reported that water-extracted Astragalus was effective in the prevention of frequent episodes of acute respiratory tract infection in children. This compensated for the problem of "blood deficiency" [17]. The extract of Astragalus root given orally stimulated the immune system, increased the production of white blood cells, also accelerated peripheral blood mononuclear cells and cytokine proliferation [18]. It significantly decreased soluble interleukin-2 receptor (sIL-2R) and interleukin-8 levels but increased the level of $\operatorname{Ig} \mathrm{A}$, IgM, and IgG to prevent upper respiratory tract infections (URTIs) [19].

\section{Astragalus saponins}

There was another research about the exploration of clinical research on Astragalus in the treatment of respiratory system disease after SARS occurrence in 2003. Lu Y et al. discovered that Astragalus saponins (in a dose of $50 \mathrm{mg} \mathrm{kg}^{-1}$ daily) increased blood flow in the lungs, improved pulmonary circulation, and took some inflammatory substances or toxins away from the blood. This helped stabilize and reduce inflammatory exudation of cell membranes and lysosomal membranes. Moreover, Astragalus saponins significantly increased cardiac output, pulse volume, and cardiac index, which led to improve the hypoxia tolerance of myocardium. It had vasodilatory and diuretic effects, which was beneficial to reduce cardiac load and its cardiac function promoting pulmonary circulation. Astragalus saponins also inhibited the STAT3 signal transition pathway for virus replication. It regulated the immune system to make $\mathrm{T}$ cells, $\mathrm{B}$ cells, and monocytes played a synergistic effect to improve the body's non-specific or specific immune functions and enhance the ability to resist pathogens [20-21]. In 2016, Wang Y et al. reported that Astragalus saponins inhibited lipopolysaccharide-induced inflammation in mouse macrophages, also suppressed the LPS-induced iNOS and TNF- $\alpha$ expression in the mouse macrophage RAW264.7 by the inhibition of p38 MAPK/NF- $\kappa$ B signaling [22].

\section{Astragalus polysaccharides}

Astragalus polysaccharide was one of the bioactive constituents of Astragalus. He X et al. proved that there was an anti-inflammatory activity of Astragalus polysaccharides with the concentrations of 50 , 100 , and $200 \mu \mathrm{g} / \mathrm{ml}$ ) for $24 \mathrm{~h}$. It suppressed NF- $\kappa \mathrm{B}$ activation and down-regulated the phosphorylation of ERK and JNK to induce the production of TNF- $\alpha$ and IL-1 $\beta$ [23]. Shao BM et al. also reported that Astragalus polysaccharide activated mouse macrophages through triggering TLR4-mediated signaling pathways. It upregulated the expression of p-p38, p-ERK, p-JNK, induced I $\kappa \mathrm{B}-\alpha$ degradation, and NF- $\kappa$ B translocation to enhance the production of TNF- $\alpha$, IL-6, and NO for anti-inflammatory purposes [24]. Lu J et al. showed that Astragalus polysaccharide in the concentrations of 100, 200, 400, and $800 \mu \mathrm{g} / \mathrm{ml}$ induced IL-10 protein production and gene expression of anti-inflammatory interleukin (IL)-10, macrophage mannose receptor (MMR), dectin-1, arginase, YM-1, and YM-2. It inhibited IL- $1 \beta$ protein production and expressed some proinflammatory genes, such as IL- $1 \beta$, iNOS, MCP-1, IL-6, and CD11c. This was effective to inhibit the pro-inflammatory responses through AMP-activated protein kinase (AMPK) activity [25]. Recently, a research team from the Southern University of 
Science and Technology (SUSTech) found that a mix of Astragalus polysaccharides and strontium could be further developed into an anti-inflammatory drug for the COVID-19 infection or its mutation viruses [26].

\section{Traditional Chinese medicine theory of Astra- galus action}

Based on traditional Chinese medicine theory, COVID-19 epidemic consists of external and internal factors regarding the evil of human infectious diseases and lack of the human body's righteousness. These were the principles derived from Nathan et al. [27]: keep healthy and do not be evil. "Eliminate" the evil by killing or inhibiting the virus, and "strengthen" the immune system by regulating human organs to achieve the antiviral effect. Astragalus is one of the traditional Chinese herbs able to "eliminate" evil and "strengthen" the immune system.

\section{Possible mechanism of Astragalus in COVID-19}

Growing evidence has shown that Astragalus is suitable for the prevention of COVID-19. The COVID-19 infection is caused by the SARS-CoV-2 virus, which binds to an angiotensin-converting enzyme 2 (ACE2) receptor of spike glycoprotein. The transmembrane protease serine 2 (TMPRSS2) and a disintegrin metallopeptidase domain 17 (ADAM17) interact. Infected cells and inflammatory cells are stimulated by viral antigens. It produces pro-inflammatory cytokines (PICs) and chemokines to activate immune and inflammatory responses. The macrophage-phagocytosed viruses can be transmitted to other organs through blood. A high level of angiotensin-converting enzyme 2 (ACE2) expression increases the lung vascular permeability causing pulmonary oedema, however, it could protect angiotensin-converting enzyme 2 (ACE2) or angiotensin-(1-7) or MAS axis in the lungs that alleviates lung inflammation, fibrosis, and pulmonary arterial hypertension, as well as inhibits tumor angiogenesis. However, the SARS-CoV-2 virus reduces the expression of angiotensin-converting enzyme 2 (ACE2) in the lung and cannot achieve the protect function. It is generally believed that COVID-19 first invades the human lungs and spleen, then attacks the heart [28]. In 2009, Yan P et al. reported that Radix Astragali enhanced the metabolic syndrome in the kidney of rats through the angiotensin-converting enzyme 2 (ACE2). The expression of ACE2 mRNA decreased in the kidney of a rat which explained that Radix Astragali dose-dependently increased the expression of ACE2 in the rat kidney [29]. This also had been elucidated that Astragalus possessed pharmacological significance for the prevention and treatment of COVID-19.

\section{CONCLUSION}

All of the above information demonstrates that traditional Chinese herb, Astragalus might be useful in the treatment and prevention of COVID-19 as it affects the anti-inflammatory activity. However, much more work needs to be done such as clinical trials because the current state of research on Astragalus is only a scientific premise according to traditional Chinese medicine theory.

Ethical approval: The conducted research is not related to either human or animal use.

Conflict of interest: Authors declare no conflict of interest.

\section{REFERENCES}

1. WHO announces COVID-19 outbreak a pandemic, 2020. https://www.euro.who.int/en/healthtopics/health-emergencies/coronavirus-covid-19/ news/news/2020/3/who-announces-covid19-outbreak-a-pandemic (accessed 29 Aug 2020).

2. Zhao S, Lin Q, Ran J, Musa SS, Yang G, Lou YJ, et al. Preliminary estimation of basic reproduction number of novel coronavirus (2019-nCoV) in China, from 2019 to 2020: a data-driven analysis in the early phase of the outbreak. Int J Infect Dis 2020; 92:214-217. doi: http://dx.doi. org/10.1016/j.ijid.2020.01.050

3. COVID-19 Coronavirus pandemic, 2020. https://www.worldometers.info/coronavirus/?utm campaign=homeAdUOA?Si (accessed 29 Aug 2020).

4. Lurie N, Saville M, Hatchett R, Halton J. Developing Covid-19 vaccines at pandemic speed 2020. N Engl J Med 2020; 382(21):1969-1973. doi: http:// dx.doi.org/10.1056/NEJMp2005630 
5. National health commission of the People's Republic of China, Guideline on diagnosis and treatment of COVID-19 (Trial 7th edition), 2020. Available from: http://en.nhc.gov.cn/202003/29/c_78469.htm (accessed 29 Aug 2020).

6. Mabberly DJ. The plant book. $2^{\text {nd }}$ ed. Cambridge 1997.

7. Lui QD. New compilation of materia medica. Shanghai 2000.

8. National Center for Complementary and Integrative Health (NIH): Astragalus, 2020. https://www. nccih.nih.gov/health/astragalus (accessed 29 Aug 2020).

9. McKenna D, Hughes K, Jones K. Astragalus. Altern Ther Health Med 2002;8(6):34-40.

10. Chu DT, Wong WL, Mavligit GM. Fractionated extract of Astragalus membranaceus, a Chinese medicinal herb, potentiates LAK cell cytotoxicity generated by a low dose of recombinant interleukin-2. J Clin Lab Immunol 1988; 25(3):119-123.

11. Yang Y, Wang LD, Chen ZB. Effects of Astragalus membranaceus on TH cell subset function in children with recurrent tonsillitis. Zhongguo Dang Dai Er Ke Za Zhi 2006; 8(5):376-378.

12. Block KI, Mead MN. Immune system effects of Echinacea, Ginseng, and Astragalus: A review. Integr Cancer Ther 2003; 2(3):247-267. doi: http:// dx.doi.org/10.1177/1534735403256419

13. McCulloch M, See C, Shu X, et al. Astragalusbased Chinese herbs and platinum-based chemotherapy for advanced non-small-cell lung cancer: meta-analysis of randomized trials. J Clin Oncol 2006; 24(3):419-430. doi: http://dx.doi. org/10.1200/JCO.2005.03.6392

14. Romm A, Clare B, Alschuler L, et al. Vaginal infections and sexually transmitted diseases. Botan Med Women's Health 2010; 54(4):256-289.

15. Lin Y, Wang B, Luo X. Clinical study of Astragalus's preventing the recurrence of asthma in children. Zhongguo Zhong Xi Yi Jie He Za Zhi 2011; 31(8):1090-1092.

16. Zou C, Su G, Wu Y, et al. Astragalus in the prevention of upper respiratory tract infection in chil- dren with nephrotic syndrome: Evidence-based clinical practice. Evid Based Complement Alternat Med 2013; 2013:352130. doi: http://dx.doi. org/10.1155/2013/352130

17. Su G, Chen X, Liu Z, et al. Oral Astragalus (Huang qi) for preventing frequent episodes of acute respiratory tract infection in children. Cochrane Database Syst Rev 2016;12(12):CD011958. doi: http://dx.doi.org/10.1002/14651858.CD011958. pub2

18. Wang RT, Shan BE, Li QX. Extracorporeal experimental study on immuno-modulator activity of Astragalus membranaceus extract. Chin J Integr Tradit Westmed 2002; 6:453-456.

19. Nie LF, Yi P. Huangqi influence SIL-2R, IL-8 and immuno-globin in patient with recurrent respiratory tract infection. Cell Mol Immunol 2009; 25(4):362-363.

20. To improve your own disease resistance and fight the epidemic, Huangqi granules are your first choice! 2020. http://jgz.app.todayguizhou.com/news/news-news_detail-news_id11515115135816.html (accessed 29 Aug 2020).

21. Lu Y. Astragalus treatment of respiratory diseases clinical progress. J Pract Trad Chin Intern Med 2009; 12:27-29.

22. Wang Y, Ren T, Zheng L, et al. Astragalus saponins inhibits lipopolysaccharide-induced inflammation in mouse macrophages. Am J Chin Med 2016;44:579-593. doi: http://dx.doi.org/10.1142/ S0192415X16500324

23. He X, Shu J, Xu L, et al. Inhibitory effect of Astragalus polysaccharides on lipopolysaccharideinduced TNF- $\alpha$ and IL- $1 \beta$ production in THP-1 cells. Molecules 2012; 17:3155-3164. doi: http:// dx.doi.org/10.3390/molecules 17033155

24. Shao BM, Xu W, Dai H, et al. A study on the immune receptors for polysaccharides from the roots of Astragalus membranaceus, a Chinese medicinal herb. Biochem Biophys Res Commun 2004;320:1103-1111. doi: http://dx.doi. org/10.1016/j.bbrc.2004.06.065

25. Lu J, Chen X, Zhang Y, et al. Astragalus polysaccharide induces anti-inflammatory effects dependent on AMPK activity in palmitate- 
treated RAW264.7 cells. Int J Mol Med 2013; 31(6):1463-1470. doi: http://dx.doi.org/10.3892/ ijmm.2013.1335

26. SUSTech research team develops COVID-19 drug, 2020. Available from: http://www.sz.gov. cn/en_szgov/news/infocus/pda/news/content/ post_7609909.html (accessed 29 Aug 2020).

27. Nathan S, Loewe M. Huang Ti Nei Chin. In: Loewe M. (ed.). Early Chinese texts: a bibliographical guide. Berkeley and Los Angeles 1993:196-215.
28. Ni W, Yang X, Yang D, et al. Role of angiotensinconverting enzyme 2 (ACE2) in COVID-19. Crit Care 2020; 24:422. http://dx.doi.org/10.1186/ s13054-020-03120-0

29. Yan $\mathrm{P}, \mathrm{Yu}$ J, Li J, et al. Radix astragali enhanced angiotensin-converting enzyme 2 expression in kidney in rats with metabolic syndrome. Chin J Hypertens 2009; 17(4):322-327. 